\title{
Profiling Student Teachers' Tendencies on Peer Review Production
}

\author{
Eva Rahmawati ${ }^{1, *}$ \\ ${ }^{1}$ Universitas Negeri Surabaya, Surabaya, Indonesia \\ *Corresponding author: evarahmawati@unesa.ac.id
}

\begin{abstract}
This is a report of a preliminary study focused on investigating student teachers' tendencies of peer review production. The research is a basis for a more comprehensive research aiming to explain how the aforementioned tendencies affect the effectiveness of peer review. The data collected were in the form of students' written commentaries taken from three expository and argumentative essay writing assignments. These data were collected from eight students, four high achievers and four low achievers. On the course's first meeting, an essay writing proficiency test was administered to determine research's participants and dyads involved. To prepare students with peer review practice, a peer review tutorial and rubrics were also given on the first meeting of the course. Following this stage, students' written commentaries were collected as data, which were then codified following the typology of written feedback by experts. Codification results were interpreted by comparing them to previous related research. In doing so, it was apparent that low achievers tend to produce commentaries on surface structure errors. As oppose to this, organization and content-focused commentaries were dominant in high achievers' feedbacks. These findings are noteworthy, as they suggest a link between students' proficiency level and their preferred commentary focus.
\end{abstract}

Keywords: academic writing, peer review production, student teacher, commentary provision tendency.

\section{INTRODUCTION}

Students in a teacher training program is not only expected to be successful learners, but more importantly they are learning on how to be teachers or educational instructors. Two professions which demand a comprehensive understanding on the practice of effective feedback provision. Looking at this particular need, it is apparent why this has become an urgent practical reason on why this current study needs to take place.

As an integral part of peer review practice in the teaching and learning of writing skill, students' commentaries as reviewers has taken up a great deal of attention in many research both in their nature and provision technique (Allen \& Katayama, 2016; Ruegg, 2015; Yu \& Lee, 2014, 2016). Such interest towards student commentaries in peer review is not without clear reasons as it is thought to be one of the factors that may affect student - authors decision in making their revisions (Maliborska \& You, 2016).

In fact, some previous research have been set out to investigate this issue. One research by Chong (2016) points out that there is a positive correlation between feedback accuracy and students' level of ability. This study provides an explanation on how students' proficiency 
levels affect their feedback's accuracy. In doing so, this study also implies that the quality of students' feedback or commentaries is the factor that affects student- authors' response to them.

More recently another research by Tian and $\mathrm{Li}$ (2019) provides an insight into students' perspectives as providers, receivers, and observer of peer review activity. In this study, it was revealed that the types of feedback given in peer review activities affect students' response. Additionally, this study also investigates students' preference for feedback provision.

However, one cannot discuss the hypothetical correlation between students' feedback provision and feedback uptake in peer review activities without making its classification first. In this sense, previous research which attempt to map out feedback classification become really important. In 1997, Lunsford (1997) proposes a classification system for written feedback based on seven principles of responding to a written work. Those principles are: (a) comments development and specificity; (b) focus on global or local issues; (c) level of comments' authority; (d) purposiveness; (e) attention to process; (f) rhetorical oriented; (g) attention to extra textual aspects.

More recent than Lunsford's classification is the one made by Ellis (2009). This particular study proposes a typology of written corrective feedback that classify the later into seven types of feedback, namely: (a) direct corrective feedback; (b) indirect corrective feedback; (c) metalinguistic corrective feedback; (d) unfocused corrective feedback; (e) focused corrective feedback; (f) electronic feedback; and (g) reformulation.

Accordingly, this study also attempts to profile students' commentaries (feedback) in peer review activities following the typology explained previously. As an attempt to provide a sound starting point for a more comprehensive research on students' preference in feedback provision and its effects towards students' uptake and peer review's success, the current study does not attempt to explain reasons behind students' tendencies in commentaries provision. As such, there would only be one research question in this study: "what type of commentaries provided by student teachers in peer revision processes involved in essay writing assignments?"

\section{METHOD}

As mentioned previously, the current study is a part of another more comprehensive study on how student teacher's tendency in peer review commentary production affect the effectiveness of peer review process. Due to its nature, this study itself can be seen as a preliminary endeavor to map out students commentaries in peer review activity - to see their nature and manner of provision. Consequently, it should be noted that this study would not make any attempt to further analyze the effectiveness of the commentaries (feedback) being mapped out.

To attain its objectives, the study took place in a public university that specializes in teacher training program in Indonesia. Eight participants were selected from two expository and argumentative classes taught by the same instructor. The basis of these participants' selection is their level of proficiency in writing. Those eight students then were labelled as L1 and L2 (two students with low proficiency level from the first class); L3 and L4 (two students with low proficiency level from the second class); H1 and H2 (two students with high proficiency level from the first class); and $\mathrm{H} 3$ and $\mathrm{H} 4$ (two students with high proficiency level from the second class).

There is only one type of data retrieved during the study namely students commentaries during the peer review activities. This data was collected throughout two essay writing assignments, the exemplification essay and process essay, with peer review processes incorporated in them. These two types of essay are the first patterns of essay organization learnt 
by students in the course. Following the data collection is the coding process. Serving as a guideline for this process is a feedback profiling criteria based on two distinct studies, one study by Ellis (2009) which detailed the manner of feedback provision, and another one by Lunsford (1997) which detailed the nature of commentaries given. The results of this coding process were eventually narrated and analyzed to answer the study's main question: "what type of commentaries provided by student teachers in peer revision processes involved in essay writing assignments?"

\section{FINDINGS AND DISCUSSION}

In order to answer the main question of this study about the types of comments provided by students during peer revision, the results of the profiling and coding process is narrated and analyzed in this section. To begin with, this section describes and analyzes the types of students' written comments based on the typology of feedback made by Ellis (2009). Following this description, the descriptions and analysis of said commentaries based on criteria suggested by Lunsford (1997) are also described.

\section{THE TYPES OF STUDENTS' COMMENTARIES AS SEEN FROM THEIR MANNER OF PROVISION}

Ellis (2009) in his study mentioned several types of written corrective feedback (WCF) based on their strategies of provision. The said typology includes:

- Direct Corrective Feedback (DCF) is when the correct form is given directly.

- Indirect Corrective Feedback (ICF) is when the existence of errors is indicated without giving the correct form right away.

- Metalinguistic Corrective Feedback (MCF) is when a metalinguistic clue on the nature of the error is given.

- Unfocused Corrective Feedback (UCF) is when corrections are given to all errors present in a piece of writing.

- Focused Corrective Feedback (FCF) is when corrections are given to selected types of error only.

- Electronic Feedback (EF) is when errors are indicated and a hyperlink is provided to a related file containing the sample of correct form of the errors.

- Reformulation (R) is when a native speaker is involved into paraphrasing the original text so that it will sound more native - like.

With these guidelines already prepared, the current study proceeded to categorize the participants' commentaries as can be observed in the following Table 1:

Table 1. Students' Commentaries Based on Their Manner of Provision

\begin{tabular}{ccccccccc}
\multirow{2}{*}{ Students } & \multicolumn{7}{c}{ Manner of Provision } \\
\cline { 2 - 9 } & $\boldsymbol{D C F}$ & $\boldsymbol{I C F}$ & $\boldsymbol{M C F}$ & $\boldsymbol{U} \boldsymbol{C F}$ & $\boldsymbol{F C} \boldsymbol{F}$ & $\boldsymbol{E F}$ & $\boldsymbol{R}$ \\
\hline L1 & 7 & 2 & 0 & 0 & 9 & 0 & 0 \\
\hline L2 & 7 & 7 & 1 & 0 & 15 & 0 & 0 \\
\hline L3 & 0 & 5 & 0 & 0 & 5 & 0 & 0 \\
\hline L4 & 2 & 4 & 0 & 0 & 6 & 0 & 0
\end{tabular}




\begin{tabular}{ccccccccc}
\multirow{2}{*}{ Students } & \multicolumn{7}{c}{ Manner of Provision } \\
\cline { 2 - 9 } & $\boldsymbol{D C F}$ & $\boldsymbol{I C F}$ & $\boldsymbol{M C F}$ & $\boldsymbol{U} \boldsymbol{C F}$ & $\boldsymbol{F C} \boldsymbol{E}$ & $\boldsymbol{E F}$ & $\boldsymbol{R}$ \\
\hline H1 & 21 & 18 & 2 & 0 & 41 & 0 & 0 \\
\hline H2 & 3 & 15 & 1 & 0 & 19 & 0 & 0 \\
\hline H3 & 9 & 4 & 0 & 0 & 13 & 0 & 0 \\
\hline H4 & 14 & 11 & 1 & 0 & 26 & 0 & 0 \\
\hline
\end{tabular}

In terms of favor over the use of DCF and ICF, the students with low writing proficiency level from the two classes demonstrated a significant difference. To begin with, L1 and L2 who were both from the first class, seemed to be quite indifferent towards their choice of DCF and ICF use. They used both types of comments, and one of them (L2) even used both DCF and ICF in the exactly the same frequencies. As oppose to this data, L3 and L4 who were from the second class both favored the IDF more than DCF. This contradictory finding may dismiss the assumption that students with low writing proficiency do not feel comfortable in providing immediate corrections towards their peer's errors. However, it is worth noted that most DCFs provided were for errors in grammatical aspects, such as:

“Please check your sentence. In academic activities or on academic activities"- L1

The above comment is clearly on an error in grammatical aspect - preposition to be precise. Meanwhile, for the areas being reviewed and commented on, all four of those students (L1, L2, L3, and L4) preferred to provide their comments in focused manner.

It is also worth noted that only one of these student teachers with low writing proficiency level (L2) produced a comment that can be classified as MCF:

“S + be able to"- L2

This comment was given on the first writing assignment of exemplification essay.

As for UCF, EF, and R, none of these students produced them. The absence of UCF is quite understandable, because the provision of comments in such manner would be too taxing for the students. Likewise, EF and R were not used due to obvious reasons that the students were not trained to provide them (EF) and or were not qualified to provide them (R).

Moving onto students with high writing proficiency level, namely $\mathrm{H} 1, \mathrm{H} 2, \mathrm{H} 3$, and H4, a more uniformed tendencies can be found. The profiling done to these students' commentaries revealed that DCF is indeed the most favored type of comments. Though not exclusively used, as the students were also produced ICF, the frequency of DCF being used is considerably higher than its counterpart. The later was produced two times more frequent by $\mathrm{H} 1, \mathrm{H} 3$, and $\mathrm{H} 4$. The following is an excerpt taken from one student's comments:

"Revise your sentence structure to make it more straightforward. You can convey your opinion and ask to your friend when you don't understand about the material. "- H1

From the excerpt above, one can notice that the type of error being addressed is also in grammar. However, what sets this sample apart from the DCF produced by students of low writing proficiency, is the nature of the comments given which address more complex grammatical errors. In this case, students' higher level of writing proficiency might take a greater role in determining their tendency of producing more DCF. 
The ICF produced by these students are also more varied in terms of aspects being assessed. For instance, the comments given also concern essay's organization and content, as can be seen in the following excerpt:

"It is still an assumption, make the concrete example." - H1

In addition to DCF and ICF, students with high writing proficiency level also produced a very limited number of MCF with no other types of commentaries present (UCF, EF, and R). Also, interestingly, despite their level of proficiency, none of the students produced comments which were unfocused in manner - all comments provided were FCF in nature.

Similar to students with lower writing proficiency, the absence of EF and R may be traced back to students' lack of training in producing one (EF) and inability to fulfill the criteria required to produce $\mathrm{R}$ - being a native speaker of English.

\section{THE TYPES OF STUDENTS' COMMENTARIES AS SEEN FROM THEIR CHARACTERISTICS}

Quite different from Ellis (2009), Lunsford (1997) perceives types of commentary (feedback) based on their characteristics, focus, and format in which they are given. The classification that he created can be summarized as follow:

- Based on Development and Specificity, there are two categories, namely: Undeveloped Comments (UC) is when the comments given are undeveloped and cryptic; and Developed Comments (DC) which makes specific reference to aspects of error, and more conversational in the language and structure used.

- Based on how Purposeful the comments, there are two categories: Not Purposeful Comments (NPC) which aims the comments on errors of all aspects; and Purposeful Comments (PC) that targets specific aspects of errors.

- Based on the Attention of the comments given, there are two categories: Attention on Grammatical Correctness (AGC) which basically more form-focused; and Attention on Content (AC) which are more content-focused.

- Extra Textual Response (ETR) is when the comments given also address or make connection to other aspects outside the text itself that might contribute to the quality of the text, for example: comments on authors' background knowledge or possible audience.

- Based on Issue of Control performed by the comments, there are two categories: Controlling Comments (CC) is when the comments are authoritative in nature and or non-negotiable; and Non-Controlling Comments (NCC) is when the comments are not authoritative in nature and more negotiable.

Following this classification, students' commentaries can be categorized as shown in the table:

Table 2. Students' Commentaries Based on Their Characterstics, Focus, and Format

\begin{tabular}{c|c|c|c|c|c|c|c|c|c}
\hline \multirow{2}{*}{ Students } & \multicolumn{10}{|c}{ Characteristics, Focus, and Format } \\
\cline { 2 - 11 } & $\boldsymbol{U C}$ & $\boldsymbol{D C}$ & $\boldsymbol{N P C}$ & $\boldsymbol{P C}$ & $\boldsymbol{A G C}$ & $\boldsymbol{A C}$ & $\boldsymbol{E T R}$ & $\boldsymbol{C C}$ & $\boldsymbol{N C C}$ \\
\hline L1 & 3 & 7 & 0 & 10 & 10 & 1 & 0 & 11 & 0 \\
\hline L2 & 4 & 12 & 0 & 16 & 13 & 3 & 0 & 11 & 5 \\
\hline L3 & 0 & 5 & 0 & 5 & 2 & 3 & 0 & 1 & 4 \\
\hline L4 & 0 & 6 & 0 & 6 & 4 & 2 & 0 & 3 & 3 \\
\hline
\end{tabular}




\begin{tabular}{c|c|c|c|c|c|c|c|c|c}
\hline \multirow{2}{*}{ Students } & \multicolumn{10}{c}{ Characteristics, Focus, and Format } \\
\cline { 2 - 12 } & $\boldsymbol{U C}$ & $\boldsymbol{D C}$ & $\boldsymbol{N P C}$ & $\boldsymbol{P C}$ & $\boldsymbol{A G C}$ & $\boldsymbol{A C}$ & $\boldsymbol{E T R}$ & $\boldsymbol{C C}$ & $\boldsymbol{N} \boldsymbol{C} \boldsymbol{C}$ \\
\hline $\mathrm{H} 1$ & 1 & 40 & 0 & 41 & 32 & 9 & 2 & 32 & 9 \\
\hline $\mathrm{H} 2$ & 0 & 13 & 0 & 20 & 18 & 3 & 0 & 12 & 8 \\
\hline H3 & 9 & 4 & 0 & 13 & 13 & 0 & 0 & 11 & 2 \\
\hline $\mathrm{H} 4$ & 19 & 8 & 0 & 27 & 24 & 3 & 1 & 18 & 9 \\
\hline
\end{tabular}

Based on Table 2, it is safe to say that students with low writing proficiency level mostly produced DC type of commentaries in addition to a small number of UC that students from the first class produced. It appears that the feedback training given prior to peer review practice affected students' tendency to create developed sentences in their commentaries. All of those comments were also purposeful (PC) in nature, that is to say, that the comments were given to address specific types of errors only which is mainly focused on grammar.

Regarding the focus of attention on the comments given, most students with lower writing proficiency seem to favor AGC than AC. This preference might be related to their proficiency and the extent of peer review training that they received. The same thing could be said about Extra Textual Response (ETR) comments. The absence of this type of comments is not a surprising fact, since the training given to students did not cover the provision of Extra Textual Response. In addition to the absence of ETR, students' tendency to produce comments which were controlling in nature (CC) can also be traced back to their lower writing proficiency level and their training on peer review. However, these propositions still needs further investigation which becomes the focus of an upcoming research that is more comprehensive in nature.

Slightly different results were obtained from students with higher writing proficiency levels (H1, H2, H3, and H4). It is interesting to note that $\mathrm{H} 1 \& \mathrm{H} 2$ who came from the first class, actually prefer more developed commentaries (DC) than $\mathrm{H} 3$ and $\mathrm{H} 4$ who produced undeveloped commentaries (UC):

"plus $S$ because it is "many". - H4

and

“impacts are or impact is”. - H4

These different tendencies between the two groups of students becomes intriguing as the tutorial provided for both groups covered the same material and characteristics of commentaries.

Similar to students with lower writing proficiency levels, students with higher writing proficiency levels were also showing no inclination towards NPC type of commentaries. Instead, they were all comments produced in PC style which do not target all aspects of errors.

Meanwhile, the focus of commentaries provided by H1, H2, H3, and H4 is more on grammar or form (AGC) rather than on content (AC). This result is more or less the same as the one gathered from students with lower writing proficiency levels. However, there were also some differences when one is to compare the AC comments produced by students of high writing 


\section{New Language Dimensions}

Volume 1 (1) 2020

proficiency level and those produced by students of low writing proficiency level. This difference can be observed in the following excerpts:

"I think these sentences still need more explanation."- L3

and

"This example is looks like similar with the second example. Better, change this example to the new one. Because when you add another example but it is still the same like in upper, it just like you repeat the same explanation but twice. " - H4

From the comments above, one can observe that L3 did not explain clearly how the revision should be done. On the other hand, H4 clearly making an attempt to let the writer know how to revise the segment being commented on.

Extra Textual Response (ETR) is also one type that the students rarely produced. Nonetheless, $\mathrm{H} 1$ and $\mathrm{H} 4$ were making an attempt at creating one as quoted below:

"How can a sleeping lamp could reduce the bad impact of sleep with lights on when fall asleep? Does it automatically on when we fall asleep?" - H4

The lack of ETR production is rather expected because the material of peer review training did not cover the aforementioned type of comments. However, the fact that there are students who attempted to produce ETR might be a hint for the existence of connection between students' level of writing proficiency and their tendency in producing extra textual responses.

Last but not least, in terms of control issue, students with high writing proficiency levels tend to give comments that were controlling (CC) in nature. This does not mean that they did not produce any non-controlling comments (NCC). As a matter of fact, they did produce NCC as can be exemplified by the following excerpts: "You use most of people in the first sentence. It means that more than one people. So why u use 'he'? doesn't it
should be 'according to they want'?" - H1

and

"Maybe you can revise this sentence into simple one. Maybe you can use this "Many students can pass the SIPENA score without affected of any bad impact." I don't know what the function of this sentence is for. Because it seems unfinished" - H4

From the examples above, it appears that these students attempted a more conversationalist style to approach their audience - the writer. Using the word "maybe" and questions about the writer's decision on the assessed piece of writing were some of the strategies implemented to lessen control in their comments. Other strategies also being used were by constructing suggestions as a question and starting the comments in positive tone then adding less imposing suggestions. Therefore, instead of using phrases such as "I recommend you..." or "I suggest that you..." these students opted safer and less intimidating phrases such as "why don't you ...?" Occasionally, these students were also attempted to start with praises then moving towards suggestions that were worded as the reviewers' personal opinion, for example:

"Overall, your process essay is good. Those steps above are easy to understand. You may need to revise your thesis statement. So, the reader will know what the main points that you are trying to convey in your essay. Also, please more focus on grammar rules on your writing, especially using infinitive verb." - H2 
Finally, the application of these mitigation strategies become important because it suggests the awareness on students' part as reviewers of the need to produce comments that are nonintimidating in nature while at the same time remain informative. It further suggests that these students were aware of the possibilities that their comments would be more likely to be received if they are provided in a non-controlling nature.

\section{CONCLUSION}

This smaller-scaled study managed to figure out some interesting facts about the nature of student teachers' commentaries in peer - revision process. The first of these facts is the popularity of Direct Corrective Feedback type of commentaries among students of different levels of writing proficiency. It shows that even with students of higher education level, this type of commentaries is still quite dominant. This finding helps dispel the myth that Indirect Corrective Feedback is more dominant with students of higher education level. Meanwhile, as already expected, more Developed Commentaries were more prevalent in commentaries provided by students with higher writing proficiency levels. It is also interesting to note that while most commentaries given were still focused on grammatical issue and controlling in nature, there were also some efforts made in providing non-controlling commentaries that focused more on content aspect.

These last details are important because it suggests several interesting aspects of students as reviewers. It suggests that students know what kind of comments would be more likely to be accepted and motivating, and in return, attempted to create them. In addition to this finding, the fact that regardless of their proficiency levels, students still favor direct corrective feedback and focus-on-grammar comments (AGC) over their counterparts, is a strong hint that they still value form over content.

All these findings are a part of a bigger research that seeks to understand the relationship of student teachers' background and their feedback (commentaries) preference. It is hoped that some of the unanswered questions in this research regarding students' reasons for their preference in commentaries would be answered in the aforementioned more comprehensive research. Indeed research in this field will not stop at that, but it will also attempt to explain the connection of such preference to the success rate of peer review activities. Its' findings are expected to shed some light into how a teacher-training program can benefit from the implementation of more effective and less imposing peer review practice in the long run.

\section{REFERENCES}

Allen, D., \& Katayama, A. (2016). Relative second language proficiency and the giving and receiving of written peer feedback. System, 56, 96-106. http://doi.org/10.1016/j.system.2015.12.002

Chong, I. (2016). How students' ability levels influence the relevance and accuracy of their feedback to peers: A case study. Assessing Writing. http://doi.org/10.1016/j.asw.2016.07.002

Ellis, R. (2009). A typology of written corrective feedback types. ELT Journal, 63(2), 97107. http://doi.org/10.1093/elt/ccn023

Lunsford, R. F. (1997). When Less Is More : Principles for Responding in the Disciplines, (69), 91-104.

Maliborska, V., \& You, Y. (2016). Writing Conferences in a Second Language Writing Classroom: Instructor and Student Perspectives. TESOL Journal, 7(4), 874-897. http://doi.org/10.1002/tesj.249 
Volume 1 (1) 2020

Ruegg, R. (2015). The relative effects of peer and teacher feedback on improvement in EFL students' writing ability. Linguistics and Education, 29, 73-82. http://doi.org/10.1016/j.linged.2014.12.001

Tian, L., \& Li, L. (2019). Chinese EFL learners' perception of peer oral and written feedback as providers, receivers and observers, $8416,1-19$. http://doi.org/10.1080/09658416.2018.1535602

Yu, S., \& Lee, I. (2014). An analysis of Chinese EFL students' use of first and second language in peer feedback of L2 writing. System, 47, 28-38. http://doi.org/10.1016/j.system.2014.08.007

$\mathrm{Yu}, \mathrm{S}$., \& Lee, I. (2016). Exploring Chinese students' strategy use in a cooperative peer feedback writing group. System, 58, 1-11. http://doi.org/10.1016/j.system.2016.02.005 